\title{
Does ECG Predict Cardiac Hypertrophy in American-Style Football Athletes?
}

\author{
KORY R. SEALY, STEPHANIE WHITE, JOHN P. ERWIN, THOMAS H. MEADE, \\ STEVEN E. MARTIN, JOHN S. GREEN, JONATHAN M. OLIVER, DUSTIN P. \\ JOUBERT, BRADLEY S. LAMBERT, J.P. BRAMHALL, KORY GILL, MD, DAVID WEIR, \\ BS, AND STEPHEN F. CROUSE, FACSM
}

Applied Exercise Science Laboratory; Department of Health and Kinesiology; Texas A\&M University; College Station, Texas

\section{Category: Undergraduate \\ Stephen F.Crouse(s-crouse@tamu.edu)}

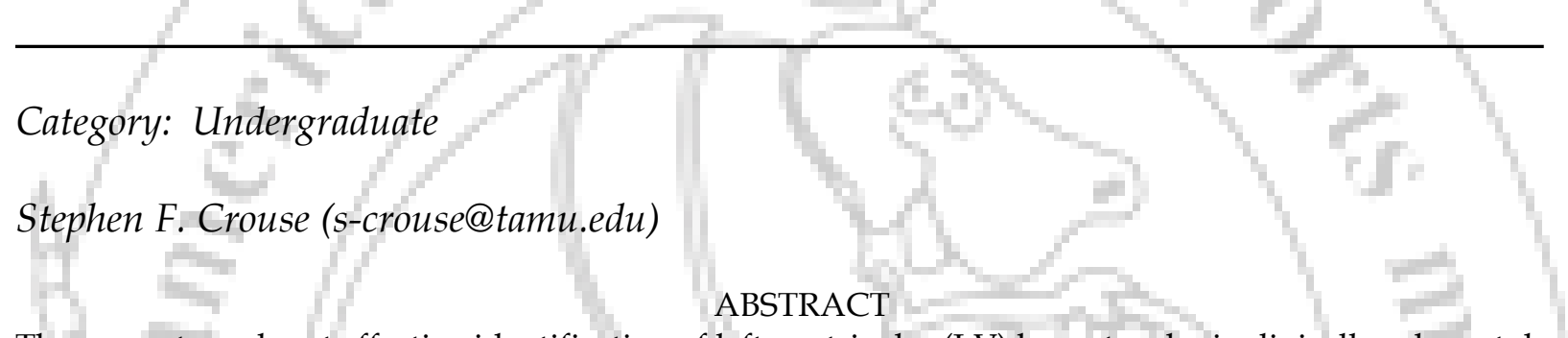

The accurate and cost effective identification of left ventricular (LV) hypertrophy is clinically relevant due to its association with cardiac mortality in the general population. PURPOSE: To determine if electrocardiographic (ECG) voltage criteria predicts LV mass measured with cardiac ultrasound in collegiate American-style football (ASF) players. METHODS: Over a 3-year period, standard resting, supine 12-lead ECG and echocardiographic $(\mathrm{ECHO})$ procedures were performed on 76 collegiate ASF players first entering an NCAA Football Bowl Subdivision university as part of their preparticipation physical exams. Player demographics were: age $=18 \pm 1$ yr., height $=186 \pm 7 \mathrm{~cm}$, weight $=100.1 \pm 22.0 \mathrm{~kg}$, $\mathrm{BMI}=28.6 \pm 5.0 \mathrm{~kg} \mathrm{~m}$, and $\mathrm{BSA}=2.24 \pm 0.25 \mathrm{~m}^{2}$. Linear regression was used to predict $\mathrm{ECHO}$-derived LV mass and LV mass/BSA index from ECG precordial-lead voltage criteria [sum largest S (V1 or V2) + R (V5 or V6) $\geq 35 \mathrm{~mm}$ ]. RESULTS: ECG voltage criteria did not significantly $(p>0.05)$ predict ECHO LV mass $\left(\mathrm{LV}\right.$ mass $\left.=-0.12 \mathrm{x}+216.94, \mathrm{r}=0.024, \mathrm{R}^{2}=0.0006\right)$, or LV mass $/ \mathrm{BSA}$ index $(\mathrm{LV}$ mass $/ \mathrm{BSA}=0.3063 \mathrm{x}+$ 81.951, $\left.\mathrm{r}=0.17, \mathrm{R}^{2}=0.0244\right)$. CONCLUSION: ECG precordial lead voltage was not clinically useful in diagnosing ECHO-derived LV hypertrophy in our sample of first-year collegiate ASF players. We suggest that new and more accurate algorithms for evaluating LV hypertrophy in ASF athletes be explored, possibly using demographic, body habitus, cardiovascular, and other ECG criteria.

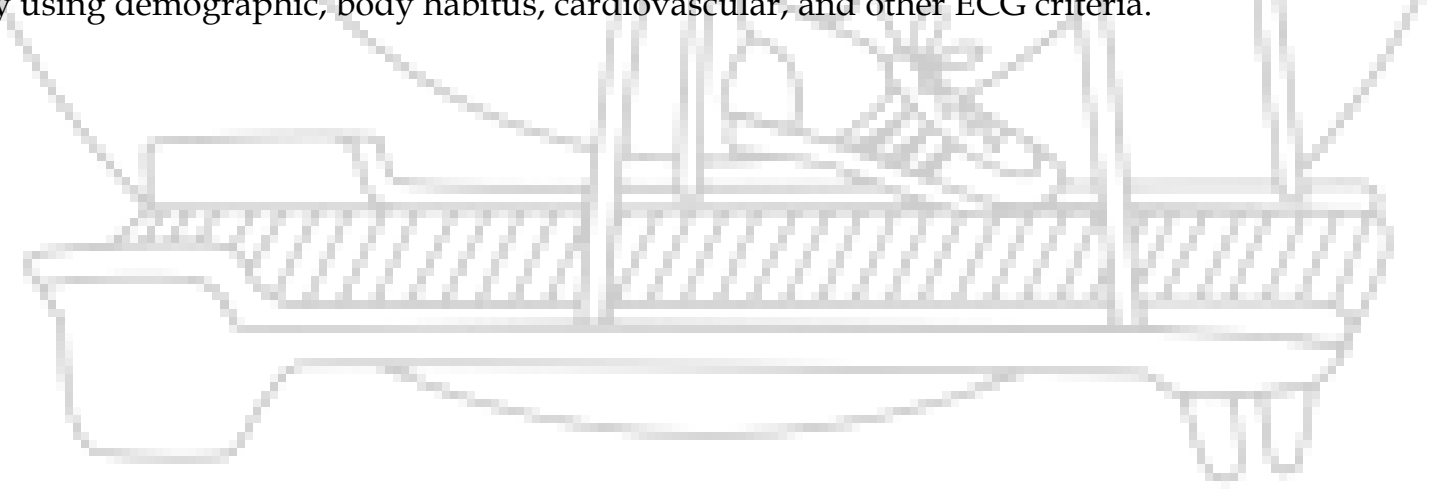

